\title{
Fluorescent lights, ultraviolet lamps, and risk of cutaneous melanoma
}

\author{
A J Swerdlow, J S C English, R M MacKie, C J O’Doherty, J A A Hunter, J Clark, D J Hole
}

\begin{abstract}
Exposure to solar radiation is increasingly being associated with a risk of cutaneous melanoma, and some risk has also been attributed to exposure to fluorescent lights. The risk of cutaneous melanoma associated with exposure to some sources of artificial ultraviolet radiation was examined in a case-control study in a Scottish population with fairly low exposure to natural ultraviolet radiation. The risk was not significantly or consistently raised for exposure to fluorescent lights at home or at work. The use of ultraviolet lamps and sunbeds, however, was associated with a significantly increased risk (relative risk $=2.9$; $95 \%$ confidence interval 1.3 to 6.4 ), and the risk was significantly related to duration of use. The risk was particularly raised among people who had first used ultraviolet beds or lamps at least five years before presentation (relative risk= $9 \cdot 1 ; 95 \%$ confidence intervals $2 \cdot 0-40 \cdot 6$ ), in whom it was significantly related to cumulative hours of exposure. The risks associated with exposure to ultraviolet lamps and sunbeds remained significant after adjustment for other risk factors for melanoma.
\end{abstract}

\section{Introduction}

Evidence suggesting that exposure to solar ultraviolet radiation is an important cause of cutaneous melanoma is increasing..$^{1.3}$ It is therefore important to investigate the risk associated with exposure to artificial sources of ultraviolet radiation, which are widely used domestically, therapeutically, and occupationally, to ascertain their safety. Such data may also help to elucidate the relation between the incidence of melanoma and different wavelengths of ultraviolet radiation and patterns of exposure, which are difficult to examine with data on exposure to solar ultraviolet radiation.

Fluorescent lights emit ultraviolet radiation whose irradiance is equal to or greater than that of sunlight at wavelengths around 290-295 $\mathrm{nm}$ but not at longer wavelengths. ${ }^{4}$ Beral et al reported a significantly increased risk of melanoma after exposure to fluorescent light at work.' Subsequent investigations, however, produced inconsistent results, so that whether such exposure is a causal factor is uncertain. ${ }^{6-10}$ Sunbeds generally deliver ultraviolet $A(320-400 \mathrm{~nm})$ at dose rates to the skin two to three times those of sunlight and may deliver ultraviolet $B(280-320 \mathrm{~nm})$ at rates near to those of bright sunlight." Ultraviolet B lamps and more recently ultraviolet $A$ lamps have been widely used for treating skin diseases and other conditions. ${ }^{12}$ Several cases of melanoma have been reported in users of sunbeds ${ }^{1314}$ and patients treated with psoralens and ultraviolet $A, 1516$ but epidemiological studies, which included only few subjects exposed to these ultraviolet sources, have been inconclusive overall. ${ }^{97-20}$

We present data on the risk of melanoma in relation to exposure to fluorescent lights, ultraviolet lamps, and sunbeds in a case-control study of a Scottish population whose exposure to solar ultraviolet radiation was probably much lower than that of most populations studied previously.

\section{Patients and methods}

The investigation was a stratum matched case control study. The cases comprised 180 patients with primary cutaneous malignant melanoma aged 15-84 who presented to the university departments of dermatology in Glasgow and Edinburgh and the west of Scotland plastic surgery unit during 1979-84; the controls were 197 hospital inpatients and outpatients with various non-malignant diseases, most commonly hypertension (55 patients), psoriasis (31), and fractures and dislocations (20). We chose hospital patients as controls because of the similar circumstances of their medical care and place of interview to those of the patients with malignant melanoma and hence the likely similarity in their attitudes and responses. We interviewed the patients with melanoma and controls with a structured interview schedule, and they were examined for benign melanocytic naevi $>2 \mathrm{~mm}$ in diameter on all body sites except the scalp and genitalia by trained dermatologists during 1983-4. The interview included questions about exposure to fluorescent light at work and at home, use of ultraviolet lamps and sunbeds, colour of hair and eyes, skin type, exposure to the sun, and occupation. We analysed the data by logistic regression with stratum matching for age (five year age groups), sex, and city where treated. ${ }^{21}$ Relative risks were examined for melanoma overall and by site and histological appearance. In the analyses of risk related to exposure to ultraviolet lamps and sunbeds we excluded all controls with dermatological conditions (77) because of the potential for bias, as their chances of past exposure may have been influenced by their skin condition.

\section{Results}

The relative risk of melanoma was slightly but not significantly raised in subjects who had been exposed to fluorescent lamps at work during the five years before presentation (relative risk $=1 \cdot 3 ; 95 \%$ confidence interval 0.9 to 2.1 ) and also in those who had usually worked under fluorescent lights before those five years (relative risk $=1.3(0.9$ to 2.1$)$ ) (table I). The risk was not raised for exposure to fluorescent light as an adult at home either in the five years before presentation $(0.7$ $(0.3$ to $1 \cdot 3))$ or before that $(0 \cdot 7(0.4$ to $1 \cdot 1))$. Very few subjects (four with malignant melanoma, six controls) stated that they had had any fluorescent lighting in their homes as children. Total average daily hours of exposure (at work and at home) to fluorescent light during the five years before presentation was not consistently related to the risk of melanoma, although the risk with five or more hours of exposure a day was just significant. Repeating the analyses with adjustment for several other risk factors for melanoma did not appreciably alter the results (table I) nor did analysis with adjustment for the same factors except numbers of naevi (not shown in table).

When exposure to fluorescent light was analysed by site of melanoma and by histological type the only significant risk was of superficial spreading melanoma, associated with exposure in the five years before diagnosis (relative risk (compared with 1.0 for no exposure $)=1.5(0.7$ to 3.4$)$ for 0.4 hours' exposure and $2.8(1.5$ to 5.4$)$ for $\geqslant 5$ hours' exposure; linear trend significant at $p<0.002$ ). This linear trend was reduced but still significant $(p<0.02)$ when adjustment was made for other risk factors for melanoma other than naevi but was not significant when adjustment was made also for the numbers of naevi.
School London

Tropical Medicine, London WCIE 7HT. 
Thirty eight patients with melanoma $(21 \%)$ but only 10 controls $(8 \%)$ had ever used ultraviolet lamps or sunbeds (relative risk $=2.9(1.3$ to $6 \cdot 4)$ ). The risk of melanoma increased significantly with duration over which exposure occurred (table II). A significant relation was evident between exposure to ultraviolet radiation use for more than five years before presentation and melanoma (relative risk $=9 \cdot 1 \quad(2 \cdot 0-40 \cdot 6)$; $\mathrm{p}<0.01$ ), and there was a significant relation between risk and cumulative hours of exposure in this period $(\mathrm{p}<0.01)$ whereas with exposure to ultraviolet radiation in the five years before presentation the risk was much lower $(1.9(0.6$ to 5.6$)$ and not related to cumulative exposure (table II). Similar results were obtained in analyses by calendar year of exposure. Risk analysed by age at first exposure was somewhat greater for people first exposed before the age of 30 compared with those exposed at a later age (table II), but the overall relation to age was not significant.

The reasons for using ultraviolet lamps or sunbeds were not known sufficiently often for analysis, and no information was available on the types of lamp or sunbed used. The relative risks associated with use of ultraviolet lamps and sunbeds were not appreciably altered by adjustment for other risk factors excluding numbers of naevi. Adjustment also for the number of naevi gave a moderate reduction in some relative risks, but the significant relation between melanoma and use of ultraviolet lamps and sunbeds remained significant (table II). Analyses of exposure to lamps and sunbeds by site of melanoma and histological type were limited to the commonest sites (leg and trunk) and histological types (superficial spreading melanoma and nodular melanoma) because of small numbers. These analyses showed no evidence of systematic variation in risk by site or histological type.

\section{Discussion}

A causal relation between fluorescent lighting and risk of melanoma would be of serious concern because of the widespread use of such lights in modern societies. Beral et al reported an increased risk of melanoma from occupational exposure to fluorescent lights, the risk being related to duration of exposure, ${ }^{5}$ but several case-control studies since then have not given consistent evidence of raised risk. Our results also do not suggest any consistent relation. Like most $^{689}$ but not all ${ }^{57}$ studies we found no significant relation between occupational or total exposure to fluorescent light and risk of melanoma overall. As in both studies that examined exposure at home separately ${ }^{59}$ we found no association of risk with such exposure, which, although often of lesser magnitude than exposure at work, may be less susceptible to reporting error..$^{22}$ In analyses by site of melanoma Beral et al found that the highest risk associated with exposure was for tumours of the trunk, ${ }^{5}$ but we, like others, found no evidence of a relation of risk to any particular site ${ }^{89}$ Analysis by the histological type of the melanoma showed that the only significant risk in our study was for superficial spreading melanoma, but

TABLE I-Relative risk of melanoma in relation to exposure to fluorescent lights

\begin{tabular}{|c|c|c|c|c|}
\hline Risk factor & $\begin{array}{l}\text { No }(\%) \text { of cases } \\
\quad(n=180)\end{array}$ & $\begin{array}{l}\text { No }(\%) \text { of controls } \\
\quad(n=197)\end{array}$ & $\begin{array}{l}\text { Unadjusted relative risk } \\
\text { ( } 95 \% \text { confidence interval) }\end{array}$ & $\begin{array}{l}\text { Adjusted relative risk } \\
\text { (95\% confidence interval) }\end{array}$ \\
\hline \multicolumn{5}{|c|}{ Exposure within five years before presentation: } \\
\hline No & $86(48)$ & $110(56)$ & $1 \cdot 0$ & $1 \cdot 0$ \\
\hline Yes & $94(52)$ & $87(44)$ & $1 \cdot 3(0.9$ to $2 \cdot 1)$ & $1 \cdot 2(0.7$ to 1.9$)$ \\
\hline \multicolumn{5}{|l|}{ At home: } \\
\hline No & $110(61)$ & $115(58)$ & & \\
\hline Yes & $70(39)$ & $82(42)$ & $0.7(0.3$ to 1.3$)$ & $0.8(0.4$ to 1.4$)$ \\
\hline \multicolumn{5}{|c|}{ At work and at home (mean hours/day): } \\
\hline 0 & $52(29)$ & $65(33)$ & $1 \cdot 0$ & $1 \cdot 0$ \\
\hline$>0-4$ & $39(22)$ & $58(29)$ & $0.8(0.5$ to 1.5$)$ & $0.7(0.4$ to 1.4$)$ \\
\hline$>5$ & $89(49)$ & $74(38)$ & $1.7(1.0$ to 2.9$) \dagger$ & $1.6(0.9$ to 2.6$)$ \\
\hline \multicolumn{5}{|c|}{ Exposure more than five years before presentation: } \\
\hline \multicolumn{5}{|c|}{ 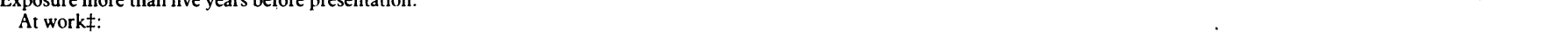 } \\
\hline No & $87(50)$ & $108(57)$ & $1 \cdot 0$ & $1 \cdot 0$ \\
\hline Yes & $86(50)$ & $83(43)$ & $1 \cdot 3(0.9$ to $2 \cdot 1)$ & $1.4(0.9$ to 2.3$)$ \\
\hline \multicolumn{5}{|l|}{ At home $\$$ : } \\
\hline No & $146(84)$ & $152(78)$ & 1.0 & $1 \cdot 0$ \\
\hline Yes & $28(16)$ & $44(22)$ & $0.7(0.4$ to $1 \cdot 1)$ & $0.8(0.4$ to 1.4$)$ \\
\hline
\end{tabular}

*Adjusted for number of naevi, skin type, colour of hair, colour of eyes, and exposure to sun.

^Adjusted for number of naevi, skin type, colour of hair, colour

$\nmid$ Relative risk significant at $\mathrm{p}<0.05$ (linear trend not significant).

Excluding six cases and one control for whom data not available.

TABLE II-Relative risks of melanoma in relation to use of ultraviolet lamps and sunbeds

\begin{tabular}{|c|c|c|c|c|}
\hline Risk factor & $\begin{array}{l}\text { No }(\%) \text { of cases } \\
\quad(n=180)\end{array}$ & $\begin{array}{l}\text { No }(\%) \text { of controls } \\
\quad(n=120)^{\star}\end{array}$ & $\begin{array}{l}\text { Unadjusted relative risk } \\
(95 \% \text { confidence interval })\end{array}$ & $\begin{array}{l}\text { Adjusted relative riskt } \\
(95 \% \text { confidence interval) }\end{array}$ \\
\hline \multicolumn{5}{|l|}{ Duration of use: } \\
\hline Never & $142(79)$ & $110(92)$ & $1 \cdot 0$ & \\
\hline$<3$ Months & $6(3)$ & $3(2)$ & $1 \cdot 2(0 \cdot 3$ to $5 \cdot 3)$ & $0.7(0.1$ to 3.8$)$ \\
\hline 3 Months to 1 year & $24(13)$ & $5(4)$ & $3.4(1.2$ to $9 \cdot 4)$ & $3.1(1.0$ to $9 \cdot 9)$ \\
\hline$>1$ Year & $8(4)$ & $2(2)$ & $4 \cdot 1(0 \cdot 8$ to $20 \cdot 3) \ddagger$ & $3.4(0.6$ to 20.3$) 8$ \\
\hline \multicolumn{5}{|c|}{ Age at first exposure (years) \|: } \\
\hline Never exposed & $142(82)$ & $110(94)$ & $1 \cdot 0$ & \\
\hline$<30$ & $17(10)$ & $3(3)$ & $4 \cdot 4(1 \cdot 2$ to $15 \cdot 7)$ & $3.8(0.9$ to $16 \cdot 5)$ \\
\hline$\geqslant 30$ & $15(9)$ & $4(3)$ & $3.0(0.9$ to $9 \cdot 6)$ & $3.2(0.7$ to 13.9$)$ \\
\hline \multicolumn{5}{|c|}{ Use in five years before presentation (cumulative hours) ||: } \\
\hline Never used & $161(93)$ & $112(96)$ & $1 \cdot 0$ & 1.0 \\
\hline $1-19$ & $6(3)$ & $2(2)$ & $2 \cdot 8(0.6$ to $14 \cdot 4)$ & $2 \cdot 1(0 \cdot 3$ to $16 \cdot 7)$ \\
\hline$\geqslant 20$ & $7(4)$ & $3(3)$ & $1 \cdot 3(0 \cdot 3$ to $5 \cdot 6)$ & $2.0(0.3$ to 13.8$)$ \\
\hline \multicolumn{5}{|c|}{ Use more than five years before presentation (cumulative hours) \#: } \\
\hline Never used & $152(87)$ & $115(98)$ & & \\
\hline $1-19$ & $16(9)$ & $2(2)$ & $6.8(1.5$ to 31.2$)$ & $4 \cdot 2(0 \cdot 8$ to $21 \cdot 8)$ \\
\hline$\geqslant 20$ & $6(3)$ & & $x \ddagger$ & $x$ \\
\hline
\end{tabular}

Excluding those with dermatological conditions.

†Adjusted for numbers of naevi, skin type, colour of hair, colour of eyes, and exposure to sun.

$\ddagger$ Linear trend significant at $p<0.01$.

SLinear trend significant at $p<0.05$.

Excludes six patients and three controls who had ever used ultraviolet for $<3$ months, for whom data were not available. 
the findings of the only other study, by English et al, to have reported histological data, did not show an increased risk for this type of melanoma. ${ }^{8}$ Conversely, we did not find any relation between exposure and risk of nodular melanoma (though this may have been due to small numbers of patients); nodular melanoma corresponds most closely to the category "unclassified melanoma" for which English et al found a significantly raised risk. ${ }^{8}$

Our data and those reported previously ${ }^{10}$ have been based on patients' histories of their exposure to fluorescent light. It would be desirable, though difficult, to verify the data on exposure by measuring the intensity of exposure at work or at home ${ }^{10}$ and useful to investigate risk from exposure to fluorescent light that, unlike exposures to lighting at work in offices and factories, has some or all of the characteristics currently thought likely to be most important in causing melanoma-that is, intermittent exposures to high doses, particularly to sites that are usually not exposed to ultraviolet radiation. ${ }^{12}$ Thus risk might be evaluated for the exposure at close range to undiffused fluorescent lights, which occurs on trains, in Britain at least.

Exposure to ultraviolet lamps and sunbeds, particularly several years before the melanoma developed, was associated with significantly increased risk in our study. Artificial ultraviolet light has been used for many years to treat a range of skin conditions, vitamin $\mathrm{D}$ deficiency, and neonatal jaundice; it was also once used to treat tuberculosis and sickly children and recently has been used increasingly to obtain a cosmetic tan at home or in commercial salons. Though previous data on the relation of ultraviolet lamps and sunbeds to the risk of melanoma have been sparse, the possibility of a causal association needs serious consideration because of both the type of exposure and its various side effects. The spectral range emitted by ultraviolet lamps varies, but the irradiance can be similar to or greater than that of solar ultraviolet radiation for parts of the spectrum. Thus treatment of psoriasis with ultraviolet B lamps can constitute 30$40 \%$ of the yearly biologically effective dose of ultraviolet $\mathrm{B}$ for outdoor workers and from $50 \%$ to almost $100 \%$ for indoor workers. ${ }^{23}$ Large doses of ultraviolet B were given to treat tuberculosis of the skin until about 40 years ago, ${ }^{12}$ and "health lamps" emitting mainly ultraviolet $\mathbf{B}^{3}$ were once widely used. Recently lamps emitting mainly ultraviolet A have become widely used: psoralen photochemotherapy, introduced in the 1970s, uses lamps emitting ultraviolet $\mathrm{A}$ and a small percentage of ultraviolet $\mathrm{B},{ }^{3}$ and sources of ultraviolet light used for cosmetic tanning emit mainly ultraviolet A or appreciable amounts of ultraviolet B and ultraviolet $\mathrm{A}^{24}$ and can produce irradiance causing erythema several times that produced by the summer noon sun at a latitude of $30^{\circ}$ or $40^{\circ} \mathrm{N} . .^{25}$ The usual pattern of exposure with ultraviolet lamps and sunbeds is high doses for short intermittent periods to skin that has not been usually exposed previously.

Ultraviolet lamps can give rise to various cutaneous side effects including sunburn from ultraviolet B treatment ${ }^{12}$; photodermatoses, especially polymorphic light eruption, from sunbeds ${ }^{11}$; and freckling from treatment with psoralens and ultraviolet $\mathrm{A}^{26}$ and probably from exposure to sunbeds. ${ }^{27} \mathrm{An}$ increased risk of skin cancer other than melanoma has been found in a follow up study of patients treated with psoralens and ultraviolet $\mathrm{A},{ }^{28}$ and immunological changes have been shown to result from exposure to sunbeds. ${ }^{29}$ Several cases of melanoma have been reported in users of sunbeds $s^{1314}$ and patients with psoriasis treated with ultraviolet radiation ${ }^{30}$ or psoralens and ultraviolet $A,{ }^{15} 16$ but evidence on the risk of melanoma has been limited and is based on small numbers. In case-control studies significantly greater of use of sunlamps or beds was reported in patients with melanoma than controls in one study ${ }^{18}$ but not in others. ${ }^{91720}$ Therapeutic exposures to ultraviolet lamps to treat acne and psoriasis were not risk factors for melanoma in one study, ${ }^{19}$ and other data that suggest that the risk of melanoma is increased for patients with psoriasis $^{3132}$ are difficult to interpret because no information was given on the type of treatment. Occupational sources of ultraviolet light were associated with an increased risk of melanoma in one study ${ }^{9}$ but not another. ${ }^{8}$

None of these studies presented data on the relation of risk to the time since exposure; thus our finding of a much increased risk and dose-response relation for use of ultraviolet lamps and beds several years before melanoma developed clearly needs reinvestigation. Such an association, however, seems generally plausible for the reasons discussed above. A specific association of exposure several years previously might suggest a long induction period for melanoma, but might also reflect the types of lamp in use before the late 1970s, which largely emitted ultraviolet B. Ultraviolet B is likely to be the carcinogenic wavelength range for melanoma as it is particularly liable to cause erythema in humans and damage to DNA and non-melanoma skin cancer in animals. ${ }^{110}$ The reduction in relative risks from ultraviolet exposure from lamps and sunbeds when adjustment was made for numbers of naevi, although leaving significant risks, is difficult to interpret until more is known about the relation of naevi to ultraviolet radiation. Reduced risk would be compatible with the idea that some naevi are an intermediate stage in the causation of melanoma by ultraviolet radiation, and seems unlikely on present knowledge to suggest confounding.

Future studies of melanoma require detailed information on the therapeutic, cosmetic, and occupational exposures of subjects to ultraviolet lamps and sunbeds that could permit analysis of the relation of the risk of melanoma to the wavelengths, timing, and duration of exposure to ultraviolet radiation, based on fairly objective data.

We thank the Greater Glasgow Health Board research support group and Eli Lilly for their financial support and the colleagues who allowed us to study their patients.

1 Elwood JM. Initiation and promotion actions of ultraviolet radiation on malignant melanoma. In: Börzsönyi $M$, Day NE, Lapis K, Yamasaki $H$, eds. Models, mechanisms and etiology of tumour promotion. Lyons: International Agency for Research on Cancer, 1984:421-40. (International Agency for Research on Cancer scientific publication No 56.)

2 Swerdlow AJ. Epidemiology of cutaneous malignant melanoma. In: MacKie RM, ed. Melanoma. London: W B Saunders, 1984:407-37. (Clinics in oncology vol 3, no 3.)

3 MacKie RM, Elwood JM, Hawk JLM. Links between exposure to ultraviolet radiation and skin cancer. $\mathcal{F} R$ Coll Physicians Lond 1987;21:91-6.

4 Maxwell KJ, Elwood JM. UV radiation from fluorescent lights. Lancet 1983;ii:579.

5 Beral V, Evans S, Shaw H, Milton G. Malignant melanoma and exposure to fluorescent lighting at work. Lancet 1982;ii:290-3.

6 Rigel DS, Friedman RJ, Levenstein M, Greenwald DI. Malignant melanoma and exposure to fluorescent lighting at work. Lancet 1983;i:704, 1290.

7 Pasternack BS, Dubin N, Moseson M. Malignant melanoma and exposure to fluorescent lighting at work. Lancet 1983;i:704.

8 English DR, Rouse IL, Xu Z, et al. Cutaneous malignant melanoma and fluorescent lighting. Fournal of the National Cancer Institute 1985;74:1191-7.

9 Elwood JM, Williamson C, Stapleton PJ. Malignant melanoma in relation to moles, pigmentation, and exposure to fluorescent and other lighting sources. Brf Cancer 1986;53:65-74.

10 Elwood JM. Could melanoma be caused by fluorescent light? A review of relevant epidemiology. In: Gallagher RP, ed. Epidemiology of malignan melanoma. Berlin: Springer-Verlag, 1986:127-36. (Recent results in cancer research vol 102.)

11 Hawk JLM. Sunbeds. Br Med f 1983;286:329.

12 Marks JM. Adverse effects of ultraviolet light therapy. Adverse Drug Reaction Bulletin 1982;95 (Aug):348-51.

13 Brodthagen H. Malignant melanoma caused by UV-A suntan bed? Acta Derm Venereol (Stockh) 1982;62:356-7.

14 Retsas S. Sun beds and melanoma. Br Med f 1983;286:892.

15 Marx JL, Auerbach R, Possick P, Myrow R, Gladstein AH, Kopf AW. Malignant melanoma in situ in two patients treated with psoralens and ultraviolet A. J Am Acad Dermatol 1983;9:904-11.

16 Kemmett D, Reshad H, Baker H. Nodular malignant melanoma and multiple 
squamous cell carcinomas in a patient treated by photochemotherapy for

17 Klepp O, Magnus K. Some environmental and bodily characteristics of melanoma patients. A case-control study. Int $\mathcal{f}$ Cancer 1979;23:482-6.

18 Adam SA, Sheaves JK, Wright NH, Mosser G, Harris RW, Vessey MP. A case-control study of the possible association between oral contraceptives and malignant melanoma. Br $\mathcal{C}$ Cancer 1981;44:45-50.

19 Elwood JM, Gallagher RP, Stapleton PJ. No association between malignant melanoma and acne or psoriasis; results from the western Canada melanoma study. Br F Dermatol 1986;115:573-6.

20 Holly EA, Kelly JW, Shpall SN, Chiu S-H. Number of melanocytic nevi as a major risk factor for malignant melanoma. I Am Acad Dermatol 1987;17:459-68.

21 Smith PG, Pike MC, Hill AP, Breslow NE, Day NE. Multivariate conditional logistic analysis of stratum-matched case-control studies. Applied Statistics 1981;30:190-7.

22 Brown AP. Melanoma and fluorescent light. Lancet 1982;ii:1398.

23 Larkö O, Diffey BL. Natural UV-B radiation received by people with outdoor, indoor, and mixed occupations and UV-B treatment of psoriasis. Clin Exp Dermatol 1983;8:279-85.

24 Devgun MS, Johnson BE, Paterson CR. Tanning, protection against sunburn and vitamin D formation with a UV-A 'sun-bed'. Br $\mathcal{I}$ Dermatol 982:107:275-84.

25 Nachtwey DS, Rundel RD. A photobiological evaluation of tanning booths Science 1981;211:405-7.

26 Swart R, Kenter I, Suurmond D. The incidence of PUVA-induced freckles. Dermatologica 1984;168:304-5.

27 MacPherson TD, Finlay AY. Ultraviolet A freckles: another hazard of sunbeds? Br Med f 1986;292:380.

28 Stern RS, Thibodeau LA, Kleinerman AB, et al. Risk of cutaneous carcinom in patients treated with oral methoxsalen photochemotherapy for psoriasis. N Engl f Med 1979;300:809-13.

29 Hersey P, Bradley M, Hasic E, et al. Immunological effects of solarium exposure. Lancet 1983; i:545-8.

30 Proctor MS, Cox AJ, Grais LS. Lentigo maligna melanoma in a treated psoriatric plaque. Arch Dermatol 1981;117:149-50.

31 Beral V, Evans S, Shaw H, Milton G. Cutaneous factors related to the risk of malignant melanoma. Br f Dermatol 1983;109:165-72.

32 Alderson MR, Clarke JA. Cancer incidence in patients with psoriasis. Brf Cancer 1983;47:857-9.

(Accepted 12 May 1988)

\title{
Evaluation of a proposed breast cancer screening regimen
}

\author{
E G Knox
}

\begin{abstract}
The Forrest working group on breast cancer screening recommended routine mammography for women in the United Kingdom at ages 50, 53, 56, 59, 62, and 65. Benefits were costed at about $£ 3000$ for each life year recovered, but there was no estimate of the cost of each life saved, and the consequent reduction in mortality from breast cancer in the general population of the United Kingdom was not estimated.

The present study addressed both of these issues using an interactive computer modelling process. Long term savings were calculated at 900 deaths a year in England and Wales-that is, about $8 \%$ of the total deaths from breast cancer-and $9 \%$ of life years currently lost. The cost of each death saved from breast cancer was estimated at $£ 39000$.
\end{abstract}

\section{Introduction}

A recent report on screening for breast cancer by the Forrest working group ${ }^{1}$ recommended introducing mammography screening in women at intervals of three years between the ages of 50 and 65 years-that is, six screens altogether. ${ }^{1}$ The age recommendation was based partly on an interpretation of earlier studies that screening is ineffective in women aged under $50^{2.5}$ and partly on the observation that older women are reluctant to attend. Economic appraisals based on projected savings of life years were considered to be favourable.

The report did.not, however, predict the long term reductions in mortality among the total population. It did not clearly distinguish between true mortality in the population and the serial cumulative differences in mortality observed in trials. Nor did the report give estimates of the cost of each death from breast cancer avoided. This paper examines these questions.

\section{Methods}

Computer based methods for predicting the outcomes of population screening for cancer were worked out many years ago, and early predictions of the effectiveness of screening for breast cancer in the United Kingdom were reported in $1975 .{ }^{67}$ The calculations were based on, firstly, age specific distributions of mortality from (or incidence of) cancer in the population; secondly, a prior knowledge or reasonable estimate of the duration and rates of progression of the different stages of the disease; and, thirdly, the sensitivity and specificity of the test, the therapeutic efficacy of the treatment, the choice of ages at which to screen, and the expected acceptance rates for specific ages.

The chief problems of applying the predictions stemmed from uncertainties about the clinical course of the early stages of cancer, and this had been a particular problem in the case of cervical cancer, as the diagnosis (by cone biopsy) itself destroyed the lesion, precluding subsequent observation of its progress. A simplified predictive method which circumvented the worst of these problems was therefore developed. ${ }^{8}$ It depended on specifying the clinical course only in cases which progressed to a particular endpoint which it was the aim to prevent-for example, death. Lesions that did not progress were not considered at all. This had disadvantages - for example, we could not then comment on the numbers of false diagnoses or unnecessary treatments. For the preventive target group, however, a clear cut relation between the premises and the outcomes could be established.

The clinical course of the target disease (for example, breast cancer) is first conceived of as comprising two non-varying periods-namely, A and B. During period $A$ the disease is susceptible to early detection and full or partial cure. In period $B$ the disease is incurable. When screening is offered at a particular age and the offer is maintained over several years it results in a subsequent dip in the mortality curve at later ages. Figure 1 illustrates this. The delay between the

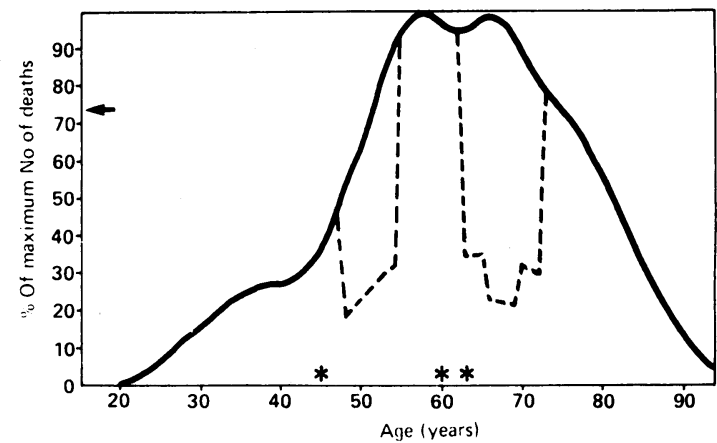

FIG 1-Method of simulation showing effects of single screen at age 45 and of two screens with overlapping "domains" at ages 60 and 63. $\star$ Screening ages and subsequent age distribution of absolute numbers of deaths. $---=$ Number of deaths after screening. $\leftarrow=$ Reduction in mortality owing to screening. Angular curves reflect fact that in this demonstration phases of clinical course were unvarying between different ages and unvarying between different women of given age. Period $A=6$ years. Period $B=3$ years 